\title{
Kajian Karakteristik Sedimen Dasar di Perairan Sungailiat untuk Mendukung Pengembangan Pelabuhan Perikanan Nusantara Sungailiat, Kab. Bangka
}

\author{
Reno Arief Rachman ${ }^{1}$, Mardi Wibowo ${ }^{2 *}$, Edwin Adi Wiguna ${ }^{1}$, Sapto Nugroho ${ }^{2}$, \\ Madyani $^{1}$, Budi Santoso ${ }^{1}$ \\ ${ }^{1}$ Balai Teknoloogi Infrastruktur Pelabuhan dan Dinamika Pantai, Badan Pengkajian dan Penerapan Teknologi \\ ${ }^{2}$ Pusat Teknologi Rekayasa Industri Maritim, Badan Pengkajian dan Penerapan Teknologi \\ Jl. Grafika No. 2, SEKIP, Yogyakarta 55284 Indonesia \\ Email: mardi.wibowo@bppt.go.id
}

\begin{abstract}
Abstrak
Tingkat sedimentasi di muara S. Jelitik sangat tinggi sehingga ketika air laut surut, kapal-kapal tidak dapat keluar masuk ke Pelabuhan Perikanan Nusantara (PPN) Sungailiat. Untuk menangani masalah tersebut, pemerintah secara periodik melakukan pengerukan yang berbiaya tinggi. Oleh karena itu, Pemprov Bangka Belitung merencanakan membangun infrastruktur pengendali sedimen. Dalam perencanaan infrastruktur pengendali sedimen diperlukan data-data karakteristik sedimen dasar. Saat ini kajian khusus karateristik sedimen dasar di kawasan ini masih belum ada. Oleh karena itu dilakukan kajian ini dengan tujuan mengetahui pola sebaran karakteristik sedimen dasar seperti berat jenis, tekstur sedimen, ukuran d50 butir sedimen dan analisis stastik sedimen dasar. Karakteristik ini sangat penting untuk kajian sedimentasi selanjutnya terutama sebagai data masukan perhitungan kecepatan sedimentasi baik secara analitik maupun dengan pemodelan numerik. Metode yang digunakan dalam kajian ini adalah survei lapangan, pengambilan sampel sedimen dasar, analisis laboratorium dan analisis statistik sedimen. Berdasarkan kajian ini sedimen dasar di perairan Sungailiat ini didominasi oleh pasir sedikit campuran kerikil dengan nilai d50 berkisar antar 1-1,5 mm dan terpilah buruk. Kondisi sedimen dasar berupa pasir mempunyai daya dukung yang baik untuk pengembangan pelabuhan.
\end{abstract}

Kata kunci: sedimentasi, sedimen dasar, sungailiat, pengendali sedimen, pelabuhan

\section{Abstract \\ Study of Sea Bottom Sediment Characteristics in Sungailiat Seawaters to Support Development of Sungaliat Fisheries Port, Bangka Regency}

Sedimentation in the S Jelitik estuary is very high, so when the tide is low, the ships traffic at the Sungailiat Fisheries Port is disturbed. So far, dredging has been done to solve this problem, which requires high costs. To overcome this, the Provincial Government of Bangka Belitung plans to build a sediment control infrastructure. In planning the sediment control infrastructure, sea bottom sediment characteristics data are needed. Currently, there is no specific study of se bottom sediment characteristics in this area. Therefore, this study was conducted with the aim of knowing the distribution pattern of seabottom sediment characteristics such as density, sediment texture, d50 grain size and analysis of the basic sediment statistics. This characteristic is very important for further sedimentation studies, especially as input data for calculating the sedimentation velocity both analytically and by numerical modeling. The methods used in this study are field surveys, sediment sampling, laboratory analysis and sediment statistical analysis. Based on this study, the seabottom sediment in Sungailiat waters is dominated by sand, a little mixture of gravel, with d50 values ranging from 1-1.5 mm and poorly segregated. The seabottom sediment in the form of sand have good capacity for port development.

Keywords: sedimentation, seabottom sediment, sungailiat, sediment control, port

*Corresponding author

DOI:10.14710/buloma.v10i2.31662 http://ejournal.undip.ac.id/index.php/buloma

Diterima/Received : 16-07-2020

Disetujui/Accepted : 25-03-2021 


\section{LATAR BELAKANG}

Erosi dan sedimentasi merupakan peristiwa alami yang saling terkait. Proses erosi diawali dengan pelepasan partikel tanah dari bongkahan batu induk atau agregatnya akibat kuatnya tetesan air hujan dan gaya aliran air. Makin besar intensitas hujan semakin besar partikel tanah yang terlepas. Proses selanjutnya adalah pengangkutan partikel tanah yang terkelupas oleh aliran air permukaan yang sangat dipengaruhi oleh kemiringan dan panjang lereng, tutupan lahan dan kecepatan aliran. Pengendapan merupakan proses jatuhnya partikel tanah yang terbawa oleh aliran permukaan di dasar perairan, hal ini sering disebut sebagai sedimentasi. Hasil sedimen adalah besarnya sedimen yang berasal dari erosi yang terjadi di daerah tangkapan air diukur pada periode waktu dan tempat tertentu (Sabri, 2017).

Perubahan tataguna lahan di Pulau Bangka telah menyebabkan bertambahnya lahan kritis di daerah penghasil timah terbesar di Indonesia ini. Maraknya aktivitas penambangan timah rakyat di Pulau Bangka diduga sebagai salah satu penyebab semakin besarnya erosi didaerah hulu dan semakin besarnya sedimentasi di daerah hilir (Sabri, 2017). Selain menyebabkan bertambahnya proses erosi dan sedimentasi penambangan timah rakyat tersebut diduga menyebabkan turunnya kualitas sumber air seperti sungai, rawa dan air kolong di Pulau Bangka (Mentari et al., 2017) serta mengakibatkan pencemaran logam berat $\mathrm{Pb}, \mathrm{Cd}$ dan $\mathrm{Cr}$ di air laut (Kurniawan et al., 2014). Hal tersebut terjadi juga di daerah aliran Sungai Jelitik di Kec Sungailiat. Sedimentasi di muara S Jelitik tergolong sangat parah sehingga ketika air laut surut, kapal-kapal tidak dapat keluar masuk ke Pelabuhan Perikanan Nusantara (PPN) Sungailiat (Wiguna et al., 2020; Wibowo dan Rachman, 2020). Permasalahan ini sudah berlangsung sejak tahun 2004 atau sudah berlangsung selama 14 tahun yang lau. Selama ini untuk menangani masalah sedimentasi dilakukan dengan melakukan pengerukan di muara Sungai Jelitik ini, hal ini membutuhkan dana yang sangat besar meskipun sebenarnya pasir hasil kerukan ini bernilai ekonomis dan dapat dijual. Saat ini Pemprov Bangka Belitung merencanakan untuk membangun infrastruktur pengendali sedimen di muara Sungai Jelitik dengan harapan dapat mengurangi kecepatan sedimentasi di muara sungai tersebut sehingga lalulintas kapal yang keluar masuk ke Pelabuhan Perikanan Nusantara (PPN) Sungailiat dapat berjalan lancar (Wibowo et al., 2020).
Dalam perencanaan bangunan pantai salah satu permasalahan utama adalah sedimentasi dan erosi. Semua bangunan pantai yang menjorok ke laut akan mengganggu keseimbangan transportasi sedimen sejajar pantai. Transpor sedimen sepanjang pantai banyak menyebabkan permasalahan seperti pendangkalan di pelabuhan, erosi pantai dan sebagainya, sehingga prediksi transpor sedimen sepanjang pantai sangat penting untuk dilakukan (Triatmodjo, 1999). Transpor sedimen di daerah dekat pantai terdiri dari transpor menuju dan meninggalkan pantai dan transpor sepanjang pantai. Penyebab utama pola arus dan gerakan sedimen di daerah pantai tertutup adalah fluktuasi muka air laut karena pasang surut. Pasang surut juga mempengaruhi elevasi tinggi gelombang yang membawa material sedimen dari dan menuju kearah pantai. Selain itu pasang surut juga berpengaruh pada kecepatan dan arah arus. Arus yang ditimbulkan oleh pasang surut cukup kuat untuk membawa material sedimen dalam jumlah yang cukup besar (Wahyudi, et al., 2004). Menurut Rifardi (2012) faktor yang mempengaruhi sedimentasi yang paling dominan adalah arus dan gelombang. Faktor lain yang mempengaruhi distribusi sedimen adalah pasang surut dan debit sungai (Dwianti et al., 2017). Menurut Khotib et al. (2013) sifat sedimen yang sangat mempengaruhi laju transpor sedimen di sepanjang pantai adalah distribusi dan gradasi butir, keohesifitas bentuk, ukuran dan densitas. Karakteristik sedimen seperti ukuran sedimen, jenis fraksi, penggolongan dalam parameter sedimen dan sebaran sedimen dapat menggambarkan kondisi lingkungan pengendapan dari beberapa faktor oseanografi yang mempengaruhi pengendapan sedimen di sekitarnya (Rifardi, 2008). Distribusi dan ketidak seragaman ukuran butiran sedimen dapat dijadikan indikator perilaku pada aliran sedimen di suatu wilayah perairan (Junaidi dan Wigati, 2011).

Selama ini kajian tentang karakteristik sedimen dasar di muara Sungai Jelitik ini belum pernah dilakukan, oleh karena itu dilakukanlah kajian tentang karakteristik sedimen dasar di perairan sekitar muara Sungai Jelitik. Pada dasarnya sedimentasi di perairan selain akibat adanya pengendapan dari sedimen yang tersuspensi juga karena pergerakan sedimen dasar yang ada di perairan tersebut. Salah satu alternatif untuk mengetahui lingkungan sedimentasi serta arah transpor sedimen dapat menggunakan parameter statistik seperti besar butir rata-rata (mean grain size), standar deviasi kepencongan (skewness) dan 
kurtosis (Affandi et al., 2012). Tujuan dari kajian ini adalah untuk mengetahui pola sebaran karakteristik sedimen dasar seperti berat jenis, tekstur sedimen, ukuran d50 butir sedimen dan analisis stastika sedimen dasar. Karakteristik ini sangat penting untuk kajian sedimentasi selanjutnya terutama untuk data masukan perhitungan kecepatan sedimentasi baik secara analitik maupun dengan pemodelan numerik dalam rencana pengembangan pelabuhan atau bangunan pelindung pantai.

\section{MATERI DAN METODE}

Penelitian ini bersifat deskriptif, yang bertujuan untuk mengetahui gambaran secara sistematis, faktual dan akurat mengenai fakta-fakta, sifat-sifat serta hubungan antara fenomena yang diselidiki (Nasir, 1983). Pengambilan contoh sedimen dilakukan dengan metode purposive sampling sebanyak 16 buah dan diambil pada bulan Mei 2018 (Gambar 2). Peralatan dan bahan yang digunakan adalah sediment grabber, kantong lastik sampel, spidol permanen \& alat tulis, piknometer, saringan, timbangan, oven, desikator (alat pendingin), termometer, bak perendam, tungku listrik, botol, hidrometer, gelas silinder, cawan porselen, alat pengaduk suspensi, stopwatch, sieve shaker, air suling (aquades), bahan dispersi (reagent). Tahapan pelaksanaan kajian ini adalah (1) Pengambilan sedimen dasar dengan menggunakan sediment grabber. (2) Penyiapan sampel sedimen dasar untuk dianalisis di laboratorium. (3) Uji laboratoriun kadar air dalam sedimen dasar, metode uji yang digunakan adalah SNI 03-1965-1990 Metode Pengujian Air Tanah (BSN, 1992). (4) Uji laboratorium berat jenis sedimen dasar, metode uji yang digunakan adalah RSNI 03-1964-1990 Metode Pengujian Berat Jenis Tanah (BSN, 1992). (5) Uji laboratorium ukuran butir sedimen dasar, metode uji yang digunakan ASTM D 422-63. (ASTM, 1998). (6) Analisis karakteristik sebaran sedimen dasar di perairan muara S. Jelitik.

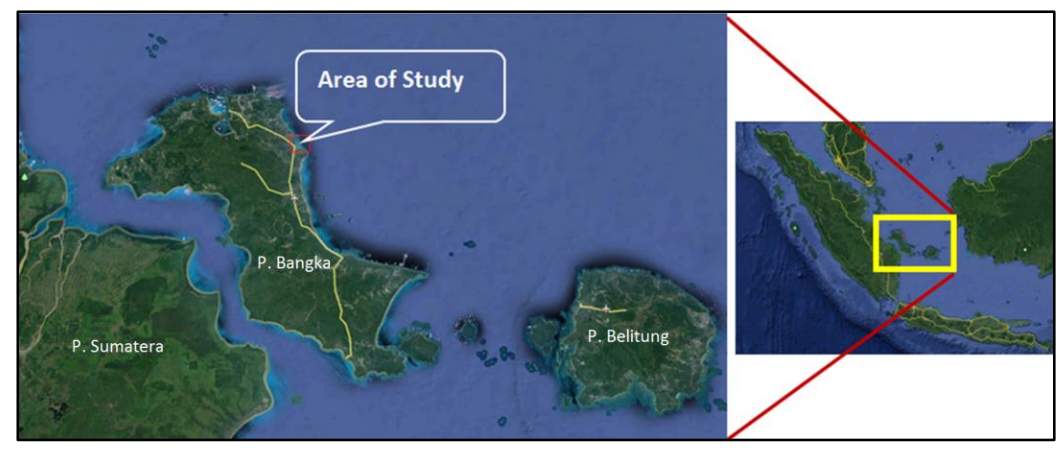

Gambar 1. Lokasi kajian

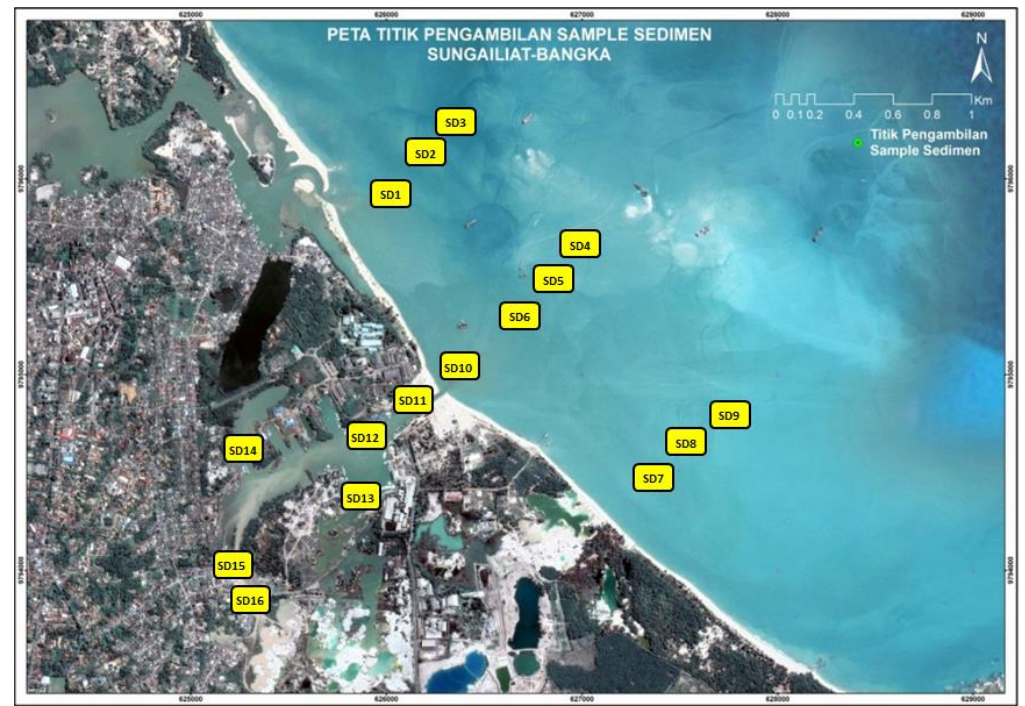

Gambar 2. Lokasi Pengambilan Sampel Sedimen Dasar sekitar muara S. Jelitik 


\section{HASIL DAN PEMBAHASAN}

\section{Karaktersitik Sedimen Dasar}

Berat jenis sedimen pada umumnya sekitar 2,65 gr/ $\mathrm{cm}^{3}$ kecuali berupa logam berat (Hambali et al., 2016). Berat jenis sedimen dasar di perairan Sungailiat berkisar 2,323-3,332 $\mathrm{gr} / \mathrm{cm}^{3}$ dengan ratarata 2,57 gr/ $\mathrm{cm}^{3}$ (lihat Tabel 1). Pola sebaran berat jenis sedimen tidak teratur akan tetapi sedimen dengan berat jenis kecil sebagian besar berada di muara sungai (SD-12), hal ini kemungkinan disebabkan pada saat pengambilan sampel tercampur dengan timah $(\mathrm{Sn})$.

Tabel 1. Berat jenis sedimen dasar $\left(\mathrm{g} / \mathrm{cm}^{3}\right)$

\begin{tabular}{ccc}
\hline No & Kode Sampel & Berat Jenis \\
\hline 1 & SD-01 & 2.502 \\
2 & SD-02 & 2.583 \\
3 & SD-03 & 2.37 \\
4 & SD-04 & 2.546 \\
5 & SD-05 & 2.402 \\
6 & SD-06 & 2.627 \\
7 & SD-07 & 2.442 \\
8 & SD-08 & 2.59 \\
9 & SD-09 & 2.323 \\
10 & SD-10 & 2.629 \\
11 & SD-11 & 2.573 \\
12 & SD-12 & 3.332 \\
13 & SD-13 & 2.55 \\
14 & SD-14 & 2.593 \\
15 & SD-15 & 2.52 \\
16 & SD-16 & 2.577 \\
\hline
\end{tabular}

Berdasarkan hasil analisis ukuran butir sedimen dan klasifikasi Segitiga Shepard diketahui bahwa sebagian besar sedimen dasar di perairan muara S. Jelitik berupa pasir dengan sedikit campuran kerikil (slighty gravelly sand) dan pasir kerikilan (gravelly sand), meskipun ada sedikit yang tercampur lumpur (muddy sandy gravel) seperti pada sampel SD-09 dan SD-12 (Tabel 3). Hal tersebut kemungkinan disebabkan oleh arus yang lebih lemah pada lokasi-lokasi dengan sedimen dasar yang lebih halus. Daerah dengan kuat arus perairan yang kuat dicirikan dengan butiran sedimen yang kasar karena pertikel halus akan terbawa dan menyebar ke tempat lain. Hal ini berarti sedimen yang berukuran kasar akan diendapkan pada lokasi yang tidak jauh dari sumbernya (Rifardi, 2008).
Hasil analisis butir sedimen menunjukkan bahwa sedimen dasar di perairan di sekitar muara $S$ Jelitik didominasi oleh fraksi pasir yang berkisar antara 51\% - 99,8\%, kecuali sampel SD-03, SD-11, SD-12 yang didominasi oleh fraksi kerikil. Secara lebih rinci fraksi pasirnya secara umum didominasi oleh fraksi pasir sedang. Fraksi lumpur yang cukup besar terdapat pada sampel SD-09 dan SD-12 yang berkisar antara 6,5-10,4\%. Komposisi dan prosentase kerikil, pasir, lanau dan lumpur dari setiap sampel sedimen disajikan pada Gambar 3, Gambar 4 dan Tabel 3.

Berdasarkan nilai d50 dari ukuran butirnya, sebagian besar sedimen dasar di perairan Sungailiat tergolong ke dalam pasir sedang (medium sand) dengan nilai d50 berkisar antara $1-1,5 \mathrm{~mm}$ (Tabel 2). Nilai d50 terkecil berada pada sampel SD-04 yang terletak di perairan laut. Nilai d50 terbesar terbesar berada pada sampel SD-16 yang terletak di aliran sungai bagian atas. Untuk mengetahui tingkat gradasi butir sedimen (variasi ukuran butir sedimen) dapat dilihat berdasarkan nilai $\sqrt{ }(\mathrm{d} 84 / \mathrm{d} 16)$ dimana semakin besar nilainya berarti semakin baik tingkat gradasi sedimen tersebut atau semakin bervariasi ukuran butir dalam sedimen tersebut.

Sedimen dasar yang dominan berukuran pasir mempunyai daya dukung yang lebih tinggi, kompresibilitas rendah dan dapat dijadikan bahan timbunan (Hettys, 2019). Sehingga di waktu yang akan datang proses pembangunan dan pengembangan pelabuhannya cukup aman. Selain itu sedimen yang berupa pasir dapat dimanfaatkan untuk meningkatkan bahan timbunan dan meningkatkan stabilitas sedimen yang ada (Saleh dan Anggraini, 2019, Simanjutak et al., 2017). Sedimen dasar pasir yang relatif kasar akan terangkut sebagai angkutan muatan dasar (bed load) bukan sebagai sedimen tersuspensi sehingga dalam perencanaan pengendali sedimen harus lebih dirancang untuk mengendalikan angkutan muatan dasar.

\section{Analisis Statistik Butiran Sedimen}

Analisis statistik digunakan untuk memaparkan distribusi frekuensi ukuran butir. Analisis statistik ukuran partikel secara umum disifatkan oleh empat parameter, yaitu mean, sorting, skewness, dan kurtosis. Nilai rata-rata (mean) dapat dikatakan sebagai rerata aritmatika dari berbagai ukuran butiran pada sampel sedimen. Nilai sorting (standar deviasi) atau lebar dari distribusi menunjukkan besarnya sebaran ukuran partikel dari nilai rata-rata sampel sedimen. Nilai 
skewness mengukur tingkat asimetris dari distribusi data. Sementara nilai kurtosis menunjukkan tingkat kepuncakan atau kedataran kurva distribusi berbanding terhadap distribusi normal (Dyer, 1986). Metode analisis statistik butir sedimen dan klasifikasi yang digunakan adalah Metode Folk dan Ward (Blott dan Pye, 2001). Hasil pengukuran nilai statistik dari ukuran butiran sedimen (Tabel 4).

Ukuran butiran rata-rata adalah sebuah indeks pengukuran ukuran butiran berdasarkan persentase berat fraksi pada tiap sampel. Hasil yang diperoleh kemudian dapat dikatakan sebagai ukuran butiran yang mewakili sampel. Ukuran butiran dapat mengindikasikan besarnya energi yang berasal dari aliran air atau angin yang bekerja di daerah tersebut (Folk dan Ward, 1957).

Secara keseluruhan, ukuran butir rerata sedimen di perairan muara S Jelitik berkisar antara 397,5-6511,2 $\mu \mathrm{m}$. Sedimen tersebut sebagai tergolong pasir sedang (medium sand) dan hanya

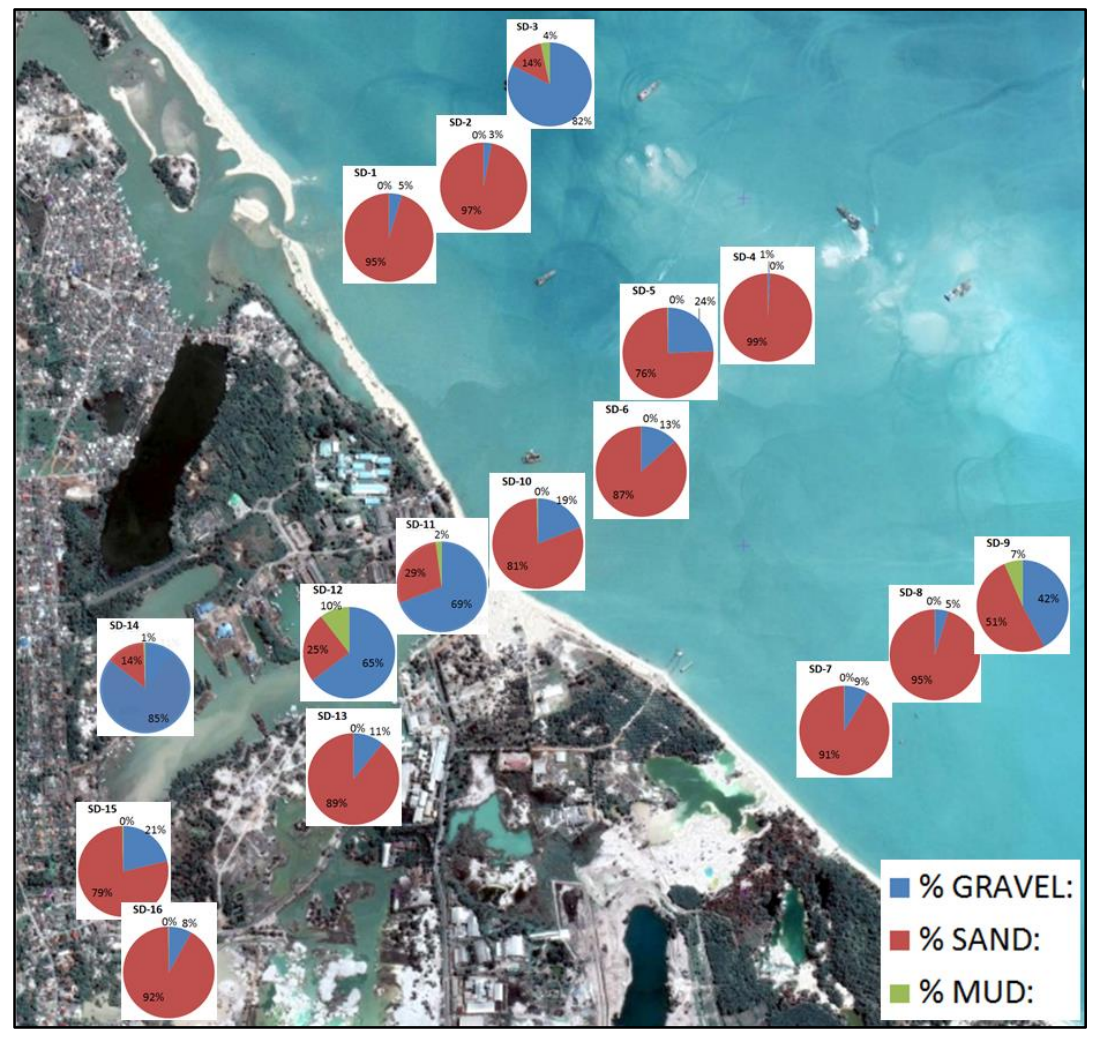

Gambar 3. Peta distribusi fraksi sedimen dasar di setiap lokasi

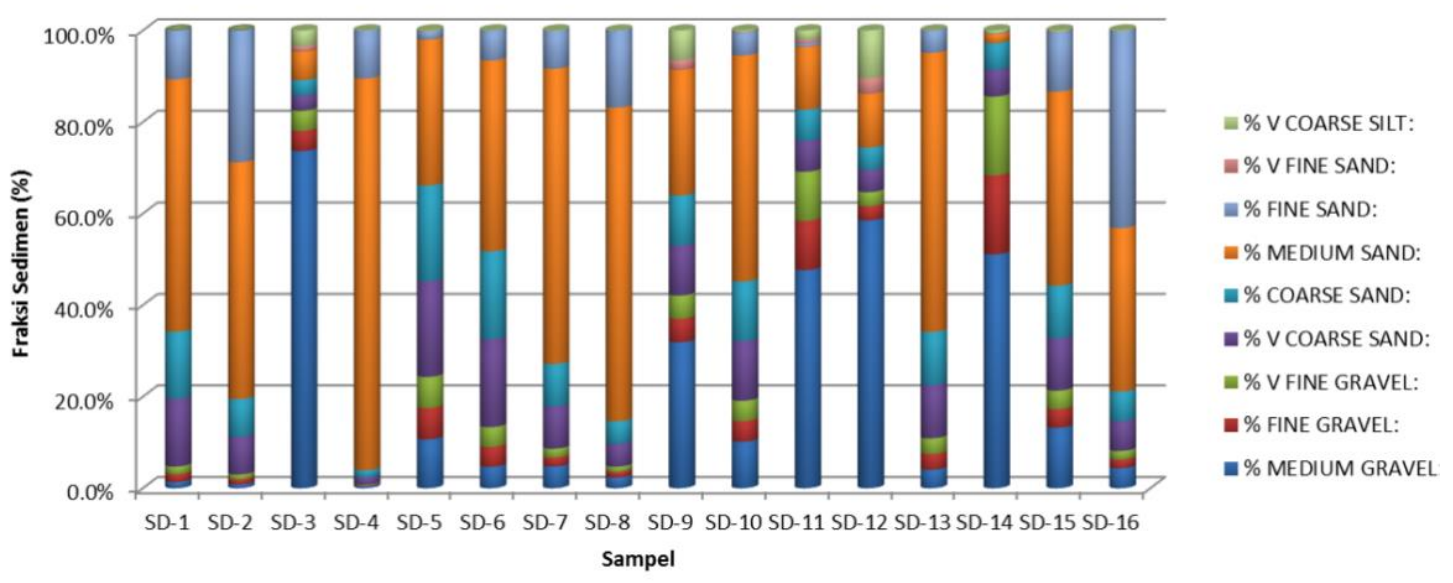

Gambar 4. Grafik distribusi fraksi sedimen dasar di perairan muara S Jelitik 
sedikit yang tergolong pasir kasar (very fine sand) (lihat Tabel 3). Nybakken (1992) menyatakan bahwa perairan yang memiliki sedimen dasar berukuran pasir menunjukkan bahwa arus pada daerah tersebut cukup kuat sehingga mampu membentuk endapan sedimen pasir. Rifardi (2012) juga menyatakan bahwa jika suatu sedimen didominasi oleh butir sedimen kasar, maka hal ini mengindikasikan kekuatan aliran yang mengangkut sedimen tersebut cukup besar, sebaliknya jika didominasi oleh sedimen berukuran halus menggambarkan lemahnya kekuatan atau energi yang mengangkut sedimen tersebut.

Pemilahan atau sortasi menggambarkan tingkat keseragaman butiran sedimen. Semakin kecil nilai sortasi menunjukkan bahwa sedimen semakin tersortasi dengan baik sehingga ukuran butir sedimennya semakin seragam, sebaliknya jika nilai sortasinya semakin besar. Penyortiran dapat menunjukkan batas ukuran butir, tipe pengendapan, karakteristik arus pengendapan, serta lamanya waktu pengendapan dari suatu populasi sedimen (Rifardi, 2012). Secara umum ada 2 kelompok utama yaitu well sorted sediment (terpilah baik) adalah suatu lingkungan pengendapan sedimen disusun oleh besar butir relatif sama, mengidentifikasikan tingkat kestabilan arus pada perairan tersebut cukup stabil. Sebaliknya jika poorly sorted sediment (terpilah buruk), maka kekuatan arus pada perairan tersebut tidak stabil, artinya pada kondisi waktu tertentu terjadi arus dengan kekuatan yang besar dan berubah dalam kondisi lain melemah kembali.

Berdasarkan hasil analisis ini, sedimen dasar di perairan sekitar muara $\mathrm{S}$ Jelitik sebagian besar tergolong dalam poorly soorted sedimen (sedimen terpilah buruk) - moderately sorted (terpilah sedang). Hanya pada lokasi SD-03 dan SD-04 saja yang tergolong well sorted (terpilah baik). Hal tersebut menunjukkan bahwa kekuatan arus pada perairan tersebut tidak stabil, artinya pada kondisi waktu tertentu terjadi arus dengan kekuatan yang besar dan berubah dalam kondisi lain melemah kembali. Hal ini sesuai dengan penelitian Edwin et al. (2020) yang menyatakan bahwa kecepatan arus sangat bervariasi antara $5-70 \mathrm{~cm} / \mathrm{dt}$.

Menurut Rifardi (2008), skewness menggambarkan arah dominan ukuran butir dari populasi tersebut, mungkin simetri, condong ke arah sedimen berbutir kasar atau condong ke arah berbutir halus. Sehingga skewness dapat digunakan untuk mengetahui dinamika sedimentasi. Nilai skewness positif menunjukkan suatu populasi sedimen condong berbutir halus, sebaliknya skewness negatif menunjukkan populasi sedimen condong berbutir kasar. Nilai skewness dipengaruhi oleh karakteristik gelombang dan arus sehingga nilai ini digunakan untuk menggambarkan

Tabel 2. Koefisien gradasi dan d50 sedimen dasar

\begin{tabular}{ccccc}
\hline Kode Sampel & D50 $(\mathrm{mm})$ & D84 $(\mathrm{mm})$ & D16 $(\mathrm{mm})$ & Koef Grad $\left(\sqrt{\frac{\mathbf{d} \mathbf{d} \mathbf{d}}{\mathbf{d 1 6}}}\right)$ \\
\hline SD-01 & 0.600 & 1.6 & 0.3 & 2.309401077 \\
SD-02 & 1.000 & 4 & 0.35 & 3.380617019 \\
SD-03 & 0.110 & 0.21 & 0.08 & 1.620185175 \\
SD-04 & 1.000 & 1.8 & 0.5 & 1.897366596 \\
SD-05 & 0.330 & 0.9 & 0.18 & 2.236067977 \\
SD-06 & 0.400 & 1.5 & 0.25 & 2.449489743 \\
SD-07 & 0.700 & 1.7 & 0.3 & 2.380476143 \\
SD-08 & 0.900 & 2 & 0.4 & 2.236067977 \\
SD-09 & 0.240 & 0.8 & 0.09 & 2.98142397 \\
SD-10 & 0.440 & 1.5 & 0.2 & 2.738612788 \\
SD-11 & 0.170 & 3.5 & 0.9 & 1.972026594 \\
SD-12 & 0.100 & 0.35 & 0.08 & 2.091650066 \\
SD-13 & 0.600 & 1.6 & 0.25 & 2.529822128 \\
SD-14 & 1.000 & 4 & 0.3 & 3.651483717 \\
SD-15 & 0.500 & 1.7 & 0.18 & 3.073181486 \\
SD-16 & 1.500 & 5 & 0.3 & 4.082482905 \\
\hline
\end{tabular}


Buletin Oseanografi Marina Juni 2021 Vol 10 No 2:112-122

Tabel 3. Hasil analisis tekstur sedimen dasar

\begin{tabular}{|c|c|c|c|c|c|c|c|c|}
\hline & SD-01 & SD-02 & SD-03 & SD-04 & SD-05 & SD-06 & SD-07 & SD-08 \\
\hline TEXTURAL GROUP: & $\begin{array}{c}\text { Slightly } \\
\text { Gravelly } \\
\text { Sand } \\
\end{array}$ & $\begin{array}{c}\text { Slightly } \\
\text { Gravelly } \\
\text { Sand }\end{array}$ & Gravel & $\begin{array}{c}\text { Slightly } \\
\text { Gravelly } \\
\text { Sand }\end{array}$ & $\begin{array}{c}\text { Gravelly } \\
\text { Sand }\end{array}$ & $\begin{array}{c}\text { Gravelly } \\
\text { Sand }\end{array}$ & $\begin{array}{c}\text { Gravelly } \\
\text { Sand }\end{array}$ & $\begin{array}{c}\text { Slightly } \\
\text { Gravelly } \\
\text { Sand }\end{array}$ \\
\hline $\mathrm{D}_{10}(\mu \mathrm{m}):$ & 242.2 & 179.1 & 422.3 & 244.0 & 292.7 & 262.6 & 253.6 & 203.0 \\
\hline $\mathrm{D}_{50}(\mu \mathrm{m}):$ & 374.5 & 313.4 & 12016.8 & 319.7 & 853.9 & 532.1 & 356.4 & 324.6 \\
\hline $\mathrm{D}_{90}(\mu \mathrm{m}):$ & 1562.6 & 1110.2 & 170730.4 & 410.1 & 8591.3 & 3421.9 & 1806.5 & 957.3 \\
\hline$\left(\mathrm{D}_{90} / \mathrm{D}_{10}\right)(\mu \mathrm{m}):$ & 6.453 & 6.199 & 404.3 & 1.681 & 29.35 & 13.03 & 7.125 & 4.717 \\
\hline$\left(\mathrm{D}_{90}-\mathrm{D}_{10}\right)(\mu \mathrm{m}):$ & 1320.4 & 931.1 & 170308.1 & 166.2 & 8298.6 & 3159.3 & 1553.0 & 754.3 \\
\hline$\left(\mathrm{D}_{75} / \mathrm{D}_{25}\right)(\mu \mathrm{m}):$ & 2.663 & 1.750 & 0.640 & 1.365 & 4.975 & 4.038 & 2.038 & 1.483 \\
\hline$\left(D_{75}-D_{25}\right)(\mu m):$ & 481.8 & 175.4 & -2335.744 & 99.95 & 1562.8 & 988.0 & 299.0 & 128.7 \\
\hline$\%$ GRAVEL: & $4.8 \%$ & $3.0 \%$ & $82.5 \%$ & $0.8 \%$ & $24.3 \%$ & $13.4 \%$ & $8.6 \%$ & $4.7 \%$ \\
\hline$\%$ SAND: & $95.2 \%$ & $97.0 \%$ & $14.1 \%$ & $99.2 \%$ & $75.5 \%$ & $86.6 \%$ & $91.3 \%$ & $95.2 \%$ \\
\hline \% MUD: & $0.0 \%$ & $0.0 \%$ & $3.5 \%$ & $0.0 \%$ & $0.2 \%$ & $0.0 \%$ & $0.1 \%$ & $0.0 \%$ \\
\hline \% V COARSE GRAVEL: & $0.0 \%$ & $0.0 \%$ & $0.0 \%$ & $0.0 \%$ & $0.0 \%$ & $0.0 \%$ & $0.0 \%$ & $0.0 \%$ \\
\hline$\%$ COARSE GRAVEL: & $0.0 \%$ & $0.0 \%$ & $0.0 \%$ & $0.0 \%$ & $0.0 \%$ & $0.0 \%$ & $0.0 \%$ & $0.0 \%$ \\
\hline \% MEDIUM GRAVEL: & $1.4 \%$ & $0.8 \%$ & $73.7 \%$ & $0.4 \%$ & $10.7 \%$ & $4.7 \%$ & $4.8 \%$ & $2.3 \%$ \\
\hline \% FINE GRAVEL: & $1.7 \%$ & $1.1 \%$ & $4.4 \%$ & $0.2 \%$ & $6.8 \%$ & $4.3 \%$ & $1.9 \%$ & $1.2 \%$ \\
\hline \% V FINE GRAVEL: & $1.7 \%$ & $1.1 \%$ & $4.4 \%$ & $0.2 \%$ & $6.8 \%$ & $4.3 \%$ & $1.9 \%$ & $1.2 \%$ \\
\hline \% V COARSE SAND: & $14.7 \%$ & $8.2 \%$ & $3.3 \%$ & $1.6 \%$ & $20.9 \%$ & $19.2 \%$ & $9.2 \%$ & $5.0 \%$ \\
\hline \% COARSE SAND: & $14.7 \%$ & $8.2 \%$ & $3.3 \%$ & $1.6 \%$ & $20.9 \%$ & $19.2 \%$ & $9.2 \%$ & $5.0 \%$ \\
\hline$\%$ MEDIUM SAND: & $55.1 \%$ & $51.7 \%$ & $6.2 \%$ & $85.6 \%$ & $31.9 \%$ & $41.7 \%$ & $64.5 \%$ & $68.5 \%$ \\
\hline$\%$ FINE SAND: & $10.6 \%$ & $28.8 \%$ & $0.0 \%$ & $10.5 \%$ & $1.7 \%$ & $6.5 \%$ & $8.2 \%$ & $16.8 \%$ \\
\hline$\%$ V FINE SAND: & $0.0 \%$ & $0.0 \%$ & $1.1 \%$ & $0.0 \%$ & $0.1 \%$ & $0.0 \%$ & $0.0 \%$ & $0.0 \%$ \\
\hline$\%$ V COARSE SILT: & $0.0 \%$ & $0.0 \%$ & $3.5 \%$ & $0.0 \%$ & $0.2 \%$ & $0.0 \%$ & $0.1 \%$ & $0.0 \%$ \\
\hline \% COARSE SILT: & $0.0 \%$ & $0.0 \%$ & $0.0 \%$ & $0.0 \%$ & $0.0 \%$ & $0.0 \%$ & $0.0 \%$ & $0.0 \%$ \\
\hline \% MEDIUM SILT: & $0.0 \%$ & $0.0 \%$ & $0.0 \%$ & $0.0 \%$ & $0.0 \%$ & $0.0 \%$ & $0.0 \%$ & $0.0 \%$ \\
\hline$\%$ FINE SILT: & $0.0 \%$ & $0.0 \%$ & $0.0 \%$ & $0.0 \%$ & $0.0 \%$ & $0.0 \%$ & $0.0 \%$ & $0.0 \%$ \\
\hline$\%$ V FINE SILT: & $0.0 \%$ & $0.0 \%$ & $0.0 \%$ & $0.0 \%$ & $0.0 \%$ & $0.0 \%$ & $0.0 \%$ & $0.0 \%$ \\
\hline$\%$ CLAY: & $0.0 \%$ & $0.0 \%$ & $0.0 \%$ & $0.0 \%$ & $0.0 \%$ & $0.0 \%$ & $0.0 \%$ & $0.0 \%$ \\
\hline
\end{tabular}


Tabel 4. Hasil analisis tekstur sedimen dasar (lanjutan)

\begin{tabular}{|c|c|c|c|c|c|c|c|c|}
\hline & SD-09 & SD-10 & SD-11 & SD-12 & SD-13 & SD-14 & SD-15 & SD-16 \\
\hline TEXTURAL GROUP: & $\begin{array}{l}\text { Muddy } \\
\text { Sandy } \\
\text { Gravel }\end{array}$ & $\begin{array}{c}\text { Gravelly } \\
\text { Sand }\end{array}$ & $\begin{array}{l}\text { Sandy } \\
\text { Gravel }\end{array}$ & $\begin{array}{l}\text { Muddy } \\
\text { Sandy } \\
\text { Gravel }\end{array}$ & $\begin{array}{c}\text { Gravelly } \\
\text { Sand }\end{array}$ & Gravel & $\begin{array}{c}\text { Gravelly } \\
\text { Sand }\end{array}$ & $\begin{array}{c}\text { Gravelly } \\
\text { Sand }\end{array}$ \\
\hline $\mathrm{D}_{10}(\mu \mathrm{m}):$ & 257.5 & 263.3 & 331.3 & 61.13 & 261.9 & 1182.0 & 219.0 & 168.5 \\
\hline $\mathrm{D}_{50}(\mu \mathrm{m}):$ & 1211.7 & 416.4 & 6879.3 & 11461.0 & 377.1 & 8358.0 & 408.0 & 277.9 \\
\hline $\mathrm{D}_{90}(\mu \mathrm{m}):$ & 19488.1 & 8212.3 & 19084.8 & 1181339.2 & 2402.2 & 12672.5 & 10360.9 & 1642.5 \\
\hline$\left(\mathrm{D}_{90} / \mathrm{D}_{10}\right)(\mu \mathrm{m}):$ & 75.68 & 31.18 & 57.61 & 19324.6 & 9.171 & 10.72 & 47.31 & 9.749 \\
\hline$\left(\mathrm{D}_{90}-\mathrm{D}_{10}\right)(\mu \mathrm{m}):$ & 19230.6 & 7948.9 & 18753.6 & 1181278.1 & 2140.3 & 11490.5 & 10141.8 & 1474.0 \\
\hline$\left(\mathrm{D}_{75} / \mathrm{D}_{25}\right)(\mu \mathrm{m}):$ & 30.06 & 4.675 & 10.72 & 8.703 & 2.874 & 3.685 & 5.483 & 2.035 \\
\hline$\left(\mathrm{D}_{75}-\mathrm{D}_{25}\right)(\mu \mathrm{m}):$ & 10303.0 & 1149.2 & 10680.7 & 3553.8 & 562.7 & 8216.8 & 1309.7 & 208.4 \\
\hline \% GRAVEL: & $42.1 \%$ & $19.1 \%$ & $69.2 \%$ & $64.7 \%$ & $10.9 \%$ & $85.6 \%$ & $21.3 \%$ & $8.2 \%$ \\
\hline$\%$ SAND: & $51.4 \%$ & $80.5 \%$ & $28.7 \%$ & $24.9 \%$ & $89.1 \%$ & $13.8 \%$ & $78.3 \%$ & $91.7 \%$ \\
\hline \% MUD: & $6.5 \%$ & $0.4 \%$ & $2.1 \%$ & $10.4 \%$ & $0.0 \%$ & $0.6 \%$ & $0.3 \%$ & $0.2 \%$ \\
\hline \% V COARSE GRAVEL: & $0.0 \%$ & $0.0 \%$ & $0.0 \%$ & $0.0 \%$ & $0.0 \%$ & $0.0 \%$ & $0.0 \%$ & $0.0 \%$ \\
\hline \% COARSE GRAVEL: & $0.0 \%$ & $0.0 \%$ & $0.0 \%$ & $0.0 \%$ & $0.0 \%$ & $0.0 \%$ & $0.0 \%$ & $0.0 \%$ \\
\hline \% MEDIUM GRAVEL: & $31.9 \%$ & $10.2 \%$ & $47.7 \%$ & $58.5 \%$ & $4.1 \%$ & $51.1 \%$ & $13.2 \%$ & $4.4 \%$ \\
\hline \% FINE GRAVEL: & $5.1 \%$ & $4.5 \%$ & $10.7 \%$ & $3.1 \%$ & $3.4 \%$ & $17.2 \%$ & $4.1 \%$ & $1.9 \%$ \\
\hline \% V FINE GRAVEL: & $5.1 \%$ & $4.5 \%$ & $10.7 \%$ & $3.1 \%$ & $3.4 \%$ & $17.2 \%$ & $4.1 \%$ & $1.9 \%$ \\
\hline \% V COARSE SAND: & $10.9 \%$ & $13.0 \%$ & $6.8 \%$ & $4.9 \%$ & $11.6 \%$ & $5.8 \%$ & $11.5 \%$ & $6.5 \%$ \\
\hline \% COARSE SAND: & $10.9 \%$ & $13.0 \%$ & $6.8 \%$ & $4.9 \%$ & $11.6 \%$ & $5.8 \%$ & $11.5 \%$ & $6.5 \%$ \\
\hline \% MEDIUM SAND: & $27.4 \%$ & $49.4 \%$ & $13.8 \%$ & $11.7 \%$ & $61.0 \%$ & $1.9 \%$ & $42.4 \%$ & $35.7 \%$ \\
\hline \% FINE SAND: & $0.0 \%$ & $5.0 \%$ & $0.7 \%$ & $0.0 \%$ & $4.9 \%$ & $0.0 \%$ & $12.9 \%$ & $43.0 \%$ \\
\hline \% V FINE SAND: & $2.1 \%$ & $0.1 \%$ & $0.7 \%$ & $3.4 \%$ & $0.0 \%$ & $0.2 \%$ & $0.1 \%$ & $0.1 \%$ \\
\hline \% V COARSE SILT: & $6.5 \%$ & $0.4 \%$ & $2.1 \%$ & $10.4 \%$ & $0.0 \%$ & $0.6 \%$ & $0.3 \%$ & $0.2 \%$ \\
\hline \% COARSE SILT: & $0.0 \%$ & $0.0 \%$ & $0.0 \%$ & $0.0 \%$ & $0.0 \%$ & $0.0 \%$ & $0.0 \%$ & $0.0 \%$ \\
\hline \% MEDIUM SILT: & $0.0 \%$ & $0.0 \%$ & $0.0 \%$ & $0.0 \%$ & $0.0 \%$ & $0.0 \%$ & $0.0 \%$ & $0.0 \%$ \\
\hline$\%$ FINE SILT: & $0.0 \%$ & $0.0 \%$ & $0.0 \%$ & $0.0 \%$ & $0.0 \%$ & $0.0 \%$ & $0.0 \%$ & $0.0 \%$ \\
\hline$\%$ V FINE SILT: & $0.0 \%$ & $0.0 \%$ & $0.0 \%$ & $0.0 \%$ & $0.0 \%$ & $0.0 \%$ & $0.0 \%$ & $0.0 \%$ \\
\hline \% CLAY: & $0.0 \%$ & $0.0 \%$ & $0.0 \%$ & $0.0 \%$ & $0.0 \%$ & $0.0 \%$ & $0.0 \%$ & $0.0 \%$ \\
\hline
\end{tabular}


Buletin Oseanografi Marina Juni 2021 Vol 10 No 2:112-122

Tabel 4. Hasil analisis statistik butiran sedimen

\begin{tabular}{|c|c|c|c|c|c|c|c|c|c|c|c|c|}
\hline \multirow[t]{2}{*}{ Sampel } & \multicolumn{4}{|c|}{ Folk And Ward Method $(\mu \mathrm{m})$} & \multicolumn{4}{|c|}{ Folk And Ward Method ( $\Phi)$} & \multicolumn{4}{|c|}{ Folk And Ward Method (Discription) } \\
\hline & Mean & Sorting & Skewness & Kurtosis & Mean & Sorting & Skewness & Kurtosis & Mean: & Sorting: & Skewness: & Kurtosis: \\
\hline SD-1 & 488.4 & 2.072 & 0.478 & 0.979 & 1.034 & 1.051 & -0.478 & 0.979 & Medium Sand & $\begin{array}{l}\text { Poorly } \\
\text { Sorted }\end{array}$ & $\begin{array}{c}\text { Very Coarse } \\
\text { Skewed }\end{array}$ & Mesokurtic \\
\hline SD-2 & 347.2 & 1.929 & 0.349 & 1.708 & 1.526 & 0.948 & -0.349 & 1.708 & Medium Sand & $\begin{array}{c}\text { Moderately } \\
\text { Sorted }\end{array}$ & $\begin{array}{c}\text { Very Coarse } \\
\text { Skewed }\end{array}$ & Very Leptokurtic \\
\hline SD-3 & 3516.6 & 1.465 & -5.288 & -1.501 & -1.814 & 0.550 & 5.288 & -1.501 & $\begin{array}{c}\text { Very Fine } \\
\text { Gravel }\end{array}$ & $\begin{array}{l}\text { Moderately } \\
\text { Well Sorted }\end{array}$ & $\begin{array}{l}\text { Very Fine } \\
\text { Skewed }\end{array}$ & Very Platykurtic \\
\hline SD-4 & 319.7 & 1.254 & -0.147 & 1.046 & 1.645 & 0.326 & 0.147 & 1.046 & Medium Sand & $\begin{array}{l}\text { Very Well } \\
\text { Sorted }\end{array}$ & Fine Skewed & Mesokurtic \\
\hline SD-5 & 1094.8 & 3.425 & 0.329 & 0.958 & -0.131 & 1.776 & -0.329 & 0.958 & $\begin{array}{c}\text { Very Coarse } \\
\text { Sand }\end{array}$ & $\begin{array}{l}\text { Poorly } \\
\text { Sorted }\end{array}$ & $\begin{array}{c}\text { Very Coarse } \\
\text { Skewed }\end{array}$ & Mesokurtic \\
\hline SD-6 & 651.6 & 2.714 & 0.416 & 1.039 & 0.618 & 1.441 & -0.416 & 1.039 & Coarse Sand & $\begin{array}{l}\text { Poorly } \\
\text { Sorted }\end{array}$ & $\begin{array}{c}\text { Very Coarse } \\
\text { Skewed }\end{array}$ & Mesokurtic \\
\hline SD-7 & 478.5 & 2.484 & 0.646 & 2.068 & 1.063 & 1.313 & -0.646 & 2.068 & Medium Sand & $\begin{array}{l}\text { Poorly } \\
\text { Sorted }\end{array}$ & $\begin{array}{c}\text { Very Coarse } \\
\text { Skewed }\end{array}$ & Very Leptokurtic \\
\hline SD-8 & 322.6 & 1.653 & 0.224 & 2.499 & 1.632 & 0.725 & -0.224 & 2.499 & Medium Sand & $\begin{array}{c}\text { Moderately } \\
\text { Sorted }\end{array}$ & Coarse Skewed & Very Leptokurtic \\
\hline SD-9 & 1628.5 & 4.435 & -0.221 & 0.443 & -0.704 & 2.149 & 0.221 & 0.443 & $\begin{array}{c}\text { Very Coarse } \\
\text { Sand }\end{array}$ & $\begin{array}{c}\text { Very Poorly } \\
\text { Sorted }\end{array}$ & Fine Skewed & Very Platykurtic \\
\hline SD-10 & 724.6 & 3.319 & 0.697 & 1.034 & 0.465 & 1.731 & -0.697 & 1.034 & Coarse Sand & $\begin{array}{l}\text { Poorly } \\
\text { Sorted }\end{array}$ & $\begin{array}{c}\text { Very Coarse } \\
\text { Skewed }\end{array}$ & Mesokurtic \\
\hline SD-11 & 3072.2 & 2.946 & -1.492 & 0.351 & -1.619 & 1.559 & 1.492 & 0.351 & $\begin{array}{c}\text { Very Fine } \\
\text { Gravel }\end{array}$ & $\begin{array}{l}\text { Poorly } \\
\text { Sorted }\end{array}$ & $\begin{array}{l}\text { Very Fine } \\
\text { Skewed }\end{array}$ & Very Platykurtic \\
\hline SD-12 & 1980.3 & 2.851 & -2.362 & 0.632 & -0.986 & 1.512 & 2.362 & 0.632 & $\begin{array}{c}\text { Very Coarse } \\
\text { Sand }\end{array}$ & $\begin{array}{l}\text { Poorly } \\
\text { Sorted }\end{array}$ & $\begin{array}{l}\text { Very Fine } \\
\text { Skewed }\end{array}$ & Very Platykurtic \\
\hline SD-13 & 536.0 & 2.496 & 0.690 & 1.272 & 0.900 & 1.320 & -0.690 & 1.272 & Coarse Sand & $\begin{array}{l}\text { Poorly } \\
\text { Sorted }\end{array}$ & $\begin{array}{c}\text { Very Coarse } \\
\text { Skewed }\end{array}$ & Leptokurtic \\
\hline SD-14 & 5994.5 & 2.007 & -1.258 & 0.545 & -2.584 & 1.005 & 1.258 & 0.545 & Fine Gravel & $\begin{array}{l}\text { Poorly } \\
\text { Sorted }\end{array}$ & $\begin{array}{l}\text { Very Fine } \\
\text { Skewed }\end{array}$ & Very Platykurtic \\
\hline SD-15 & 806.8 & 3.983 & 0.653 & 1.023 & 0.310 & 1.994 & -0.653 & 1.023 & Coarse Sand & $\begin{array}{l}\text { Poorly } \\
\text { Sorted }\end{array}$ & $\begin{array}{c}\text { Very Coarse } \\
\text { Skewed }\end{array}$ & Mesokurtic \\
\hline SD-16 & 351.7 & 2.587 & 0.574 & 2.130 & 1.508 & 1.372 & -0.574 & 2.130 & Medium Sand & $\begin{array}{l}\text { Poorly } \\
\text { Sorted }\end{array}$ & $\begin{array}{c}\text { Very Coarse } \\
\text { Skewed }\end{array}$ & Very Leptokurtic \\
\hline
\end{tabular}


kekuatan gelombang dan arus yang berperan dalam proses pengendapan. Berdasarkan hasil analisis statistik, sedimen dasar di perairan sekitar muara S Jelitik sangat bervariasi dari very coarse skewed very fine skewed dan ada yang bernilai positif dan negatif (Tabel 3). Hal tersebut menunjukkan bahwa kondisi lingkungan perairan tersebut ada yang didominasi oleh populasi sedimen yang condong berbutir kasar dan arus relatif kuat dan berbutir halus dan arus yang lemah. Arus yang kuat umumnya terjadi pada alur sungai akibat pengaruh debit sungai dari hulu, khususnya pada musim hujan. Sehingga terlihat bahwa sebaran sedimen dasar yang berbutir kasar dominan berada pada alur Sungai Jelitik seperti pada sampel SD 11, SD 12 dan SD 14 (Gambar 4)

Menurut Rifardi (2008), kurtosis mengukur puncak dari kurva dan berhubungan dengan penyebaran distribusi normal. Bila kurva distribusi normal tidak terlalu runcing atau tidak terlalu datar disebut mesokurtic. Kurva yang runcing disebut leptokurtic, menandakan adanya ukuran sedimen tertentu yang mendominansi pada distribusi sedimen di daerah tersebut. Sedangkan untuk kurva yang datar disebut platikurtic, artinya distribusi ukuran sedimen pada daerah tersebut sama. Berdasarkan hasil analisis statistik, sedimen dasar di perairan sekitar muara S Jelitik sangat bervariasi dari yang tergolong pada tipe kurtosis very platykurtic - very leptokurtic. Hal ini menunjukkan bahwa pada lokasi tertentu terdapat ukuran butir sedimen tertentu yang sangat mendominasi sedimen dan pada lokasi lain tidak ada ukuran butir sedimen tertentu yang mendominasi. Hal ini akibat kondisi arus yang dinamis dan bervariasi di perairan ini. Kecepatan arus yang bervariasi ini selain disebabkan pasang surut dan debit S. Jelitik serta dipengaruhi oleh kegiatan penambangan dengan kapal dan perahu di perairan ini (Edwin et al, 2020). Hal ini berbeda dengan kondisi sedimen dasar di sekitar perairan Patimban yang tergolong pada tipe kurtosis leptokurtic - very leptokurtic, yang artinya terdapat ukuran butir sedimen tertentu yang mendominasi sedimen di sekitar perairan Pelabuhan Patimban ini, yaitu butir sedimen pasir sangat halus (Rachman dan Wibowo, 2019).

\section{KESIMPULAN}

Berat jenis sedimen dasar di perairan Sungailiat berkisar antara 2,323-3,332 $\mathrm{gr} / \mathrm{cm}^{3}$ dengan rata-rata $2,57 \mathrm{gr} / \mathrm{cm}^{3}$ dengan pola yang tidak teratur. Sedimen dasar di perairan muara S. Jelitik dominan pasir dengan sedikit campuran kerikil (slighty gravelly sand) dan pasir kerikilan (gravelly sand) dengan d50 berkisar 1-1,5 mm dengan koefisien gradasi 1,624,08. Berdasarkan pemilahan butir sedimennya tergolong dalam poorly soorted sedimen (sedimen terpilah buruk) - moderately sorted (terpilah sedang). Berdasarkan nilai skewness-nya, sedimen dasar di muara S Jelitik sangat bervariasi dari very coarse skewed - very fine skewed. Berdasarkan nilai kurtosisnya, juga sangat bervariasi dari yang kurtosis very platykurtic - very leptokurtic. Sedimen dasar di perairan ini mempunyai daya dukung tanah yang baik untuk pengembangan pelabuhan.

\section{UCAPAN TERIMA KASIH}

Terima kasih kepada jajaran managemen Balai Teknologi Infrastruktur Pelabuhan dan Dinamika Pantai-BPPT dan kepada seluruh pelaksana kegiatan Pengkajian dan Penerapan Teknologi Rekayasa Industri Maritim-BPPT TA 2018.

\section{DAFTAR PUSTAKA}

Affandi, A.K., \& Surbakti, H. 2012. Distribusi Sedimen Dasar di Perairan Pesisir Banyuasin, Sumatera Selatan. Maspari Journal, 4(1):33-39, doi: 10.36706/maspari.v4i1.1327.

ASTM. 1998. ASTM Designation D 422-63 Standard Test Methode for Particle-Size Analysis of Soils: 8 p.

Blott, SJ., Pye, K. 2001. Technical Communication - Gradstat : A Grain Size Distribution and Statistics Package for the Analysis of Unconsolidated Sediments. Earth Surface Processes and Landforms 26:1237-1248, doi : 10.1002/esp.261.

BSN. 1992. SNI 03-1965-1990 - Metode Pengujian Kadar Air Tanah: $10 \mathrm{hlm}$.

BSN. 1992. RSNI 03-1964-1990 - Metode Pengujian Berat Jenis Tanah: $8 \mathrm{hlm}$.

Dwianti R.F., Widada, S., \& Hariadi. 2017. Distribusi Sedimen Dasar di Perairan Pelabuhan Cirebon, Jurnal Oseanografi, 6(1): 228-235.

Dyer, K.R. 1986. Coastal And Estuarine Sediment Dynamics. John Wiley dan Sons Ltd. New York: $342 \mathrm{p}$

Hambali, R., \& Apriyanti, Y. 2016. Studi Karakteristik Sedimen dan Laju Sedimentasi Sungai Daeng - Kabupaten Bangka Barat. Jurnal Fropil, 4(2):165-174.

Hettys, S. 2019. Sifat-sifat Tanah. Paparan di Balai BHGK-PUSAIR, Bandung Agustus 2019: 71 hlm 
Folk R.L. \& Ward, W.C. 1957. Brazos River Bar, A Study in The Significance of Grain-Size Parameters. Journal of Sedimentary Petrology, 27:3-26.

Junaidi \& Wigati, R., 2011. Analisis Parameter Statistik Butiran Sedimen Dasar pada Sungai Alamiah (Studi Kasus Sungai Krasak Yogyakarta). Wahana Teknik Sipil, 16(2):4657. doi: 10.32497/wahanats. v16i2.102.

Khotib, A., Adriati, Y., \& Wahyudi, A.E. 2013. Analisis Sedimentasi Dan Alternatif Penanganannya Di Pelabuhan Selat Baru Bengkalis, Makalah dalam Konferensi Nasional Teknik Sipil 7 (KoNTekS 7), 24-26 Oktober 2013, Universitas Sebelas Maret Surakarta. A31-A38.

Kurniawan, Supriharyono, \& Sasongko, DP., 2014. Pengaruh Kegiatan Penambangan Timah terhadap Kualitas Air Laut di Wilayah Peisisr Kabupaten Bangka Kepulauan Banga Belitung. Akuatik Jurnal Sumberdaya Perairan 8(1):1321.

Mentari, Umroh, \& Kuniawan. 2017. Pengaruh Aktivitas Penambangan Timah Terhadap Kualitas Air di Sungai Baturasa Kabupaten Bangka. Akuatik Jurnal Sumberdaya Perairan 11(2): 23-30. doi: 10.33019/ akuatik.v11i2.240.

Nasir, M. 1983. Metode Penelitian. Ghalia Indonesia, Jakarta: 622p.

Nybakken, J.W. 1992. Biologi Laut; Suatu Pendekatan Ekologis. PT Gramedia. 459 hlm.

Rachman, R.A. \& Wibowo, M. 2019. Study of Sea Bottom Sediment Characteristic to Support Patimban Port Development Plan, Jurnal Geologi Kelautan, 17(2):99-112.

Rifardi. 2008. Tekstur Sedimen, Sampling dan Analisis, UNRI Press Pekanbuari:101hlm.

Rifardi. 2012. Ekologi Sedimen Laut Modern. UNRI Press, Pekanbaru: $167 \mathrm{hlm}$.

Sabri, F., 2017. Kajian Erosi dan Sedimentasi Akibat Perubahan Tataguna Lahan Daerah Aliran Sungai (Studi Kasus DAS Betung Sub DAS Pebari-Jelitik Kabupaten Bangka. Prosiding Seminar Nasional Pegelolaan
Daerah Aliran Sungai Secara Terpadu 2017. Universitas Riau: 191-200.

Saleh, A. \& Anggraini, M., 2019. Metode Perbaikan Tanah Lunak dengan Penambahan Pasir. Seminar Nasional Pakar ke 2 Tahun 2019. Buku 1 : Sains dan Teknologi. 141-144.

Simanjutak, M.R.A., Lubus, K., \& Rangkuti, N.M. (2017). Stabilisasi Tanah Lempung dengan Campuran Pasir Pantai terhadap Nilai CBR. Journal of Civil Engineering, Building and Transportation 1(2) : 96-104. doi: 10.31289/ jcebt.v1i2.1680.

Siry, H.S. 2011. Studi Sebaran Sedimen Dasar Dan Pendangkalan Di Pelabuhan Minyak (Oil Wharves) PT. Caltex Pacific Indonesia Dumai, Riau Pasca Pengerukan 1990, Widyariset 14(3): 643-650. doi: 10.14203/widyariset.14.3.2011. 643-650.

Triatmodjo, B. 1999. Teknik Pantai. Penerbit BETA OFFSET, Edisi Pertama, Yogyakarta: $397 \mathrm{hlm}$

Wahyudi \& Jupantara D., 2004. Studi Simulasi Sedimentasi Akibat Pengembangan Pelabuhan Tanjung Perak Surabaya, Jurnal Teknologi Kelautan 8(2): 74-85.

Wibowo, M. \& Rachman, R.A., 2020. Kajian Kualitas Perairan Laut Sekitar Muara Sungai Jelitik Kecamatan Sungailiat - Kabupaten Bangka, Jurnal Presipitasi 17(1):29-37. doi: 10.14710/presipitasi.v17i1.29-37.

Wibowo, M., Hendriyono, W., Rachman, R.A., Susatijo, G., Kongko, W., \& Istiyanto, D.C,. (2020). Sediment Transport Modeling at Jelitik Estuary, Sungailiat - Bangka Regency for the Design of Sediment Control Structures, Journal of Physics: Conference Series 1625 2nd International Conference on Sustainable Infrastructure - IOP Publishing: $14 \mathrm{hlm}$ doi:10.1088/1742-6596/1625/1/012042.

Wiguna, EA., Wibowo, M., Rachman, RA, Aziz, H., \& Nugroho, S., 2020. Kondisi Hidrooseanografi Muara Sungai Jelitik, Sungailiat, Bangka Provinsi Bangka Belitung, Buletin Oseanografi Marina, 9(1):9-18, doi: 10.14710/buloma.v9 i1.23363. 